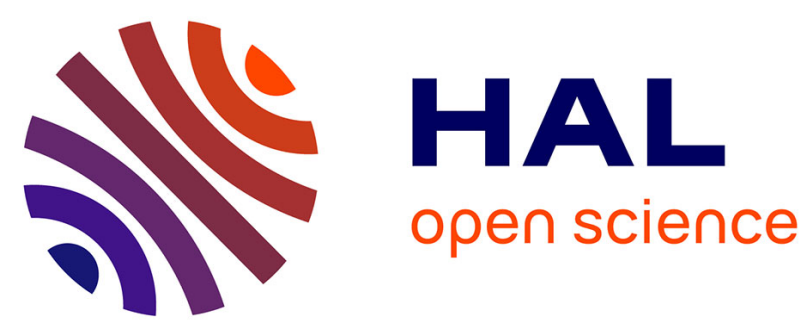

\title{
Elastic-strain distribution in metallic film-polymer substrate composites
}

\author{
G. Geandier, P.-O. Renault, E. Le Bourhis, P. Goudeau, D. Faurie,
} Christophe Le Bourlot, Ph. Djémia, Olivier Castelnau, S. M. Chérif

\section{- To cite this version:}

G. Geandier, P.-O. Renault, E. Le Bourhis, P. Goudeau, D. Faurie, et al.. Elastic-strain distribution in metallic film-polymer substrate composites. Applied Physics Letters, 2010, 96 (4), pp.1-3. 10.1063/1.3293450 . hal-01537626

\section{HAL Id: hal-01537626 \\ https://hal.science/hal-01537626}

Submitted on 25 May 2020

HAL is a multi-disciplinary open access archive for the deposit and dissemination of scientific research documents, whether they are published or not. The documents may come from teaching and research institutions in France or abroad, or from public or private research centers.
L'archive ouverte pluridisciplinaire HAL, est destinée au dépôt et à la diffusion de documents scientifiques de niveau recherche, publiés ou non, émanant des établissements d'enseignement et de recherche français ou étrangers, des laboratoires publics ou privés. 


\title{
Elastic-strain distribution in metallic film-polymer substrate composites
}

\author{
G. Geandier, ${ }^{1}$ P.-O. Renault, ${ }^{1}$ E. Le Bourhis, ${ }^{1, a)}$ Ph. Goudeau, ${ }^{1}$ D. Faurie, ${ }^{2}$ C. Le Bourlot, ${ }^{2}$ \\ Ph. Djémia, ${ }^{2}$ O. Castelnau, ${ }^{2}$ and S. M. Chérif ${ }^{2}$ \\ ${ }^{1}$ Laboratoire de Physique des Matériayx Université de Poitiers, UMR 6630 CNRS, SP2MI-Téléport 2-Bd \\ ${ }^{2}$ Lqboratoire des Propriétés. Mécaniques et Thermodynamique des Matériaux, Université Paris13,
}

\begin{abstract}
Synchrotron $\mathrm{x}$-ray radiation was used for in situ strain measurements during uniaxial tests on polymer substrates coated by a metallic gold film $400 \mathrm{~nm}$ thick deposited without interlayer or surface treatment. X-ray diffraction allowed capturing both components elastic strains and determining how these were partitioned between the metallic film and the polymeric substrate. For strains below $0.8 \%$, deformation is continuous through the metal-polymer interface while above, the onset of plasticity in the metallic film induces a shift between film and substrate elastic strains.
\end{abstract}

Understanding the mechanical behavior of nanostructured thin films in relation to their microstructure is of utmost importance for the development of technological applications. ${ }^{1}$ At nanometer length scales, mechanical properties are significantly altered. ${ }^{2}$ The processes responsible for these changes are not fully understood yet and are believed to be caused by grain-surface and grain-boundary volumes becoming dominant over the bulk. In a film, changes are further caused by boundary conditions at the free surface and interfaces. ${ }^{1,2}$ Mechanical failure of metallic stiff thin films attached to a compliant polymeric substrate poses a significant challenge in the development of integrated structures such as flexible and stretchable electronics. Mechanical behavior studies of metallic thin films deposited onto polymeric substrates mainly focused on rather large deformations. ${ }^{3,4}$ In order to enhance the adhesion of the metallic film, either the substrate surface is activated by an oxygen plasma, ${ }^{5,6}$ or an adhesion layer is deposited onto the polymer substrate with strongly reactive metals such as $\mathrm{Ti}$, $\mathrm{Cr}$, and $\mathrm{Al} .^{7,8}$ Generally, the authors supposed that the interface is strong enough to assume that deformation (in the elastic regime) is continuous through either the substrate-film interface or the interfaces within multilayers. Both from the fundamental and applicative points of view, it is of utmost importance to clarify this question. Elastic behavior can be studied by $\mathrm{x}$-ray diffraction (XRD). ${ }^{9,10}$ High intensity synchrotron $\mathrm{x}$-rays allow characterizing small volumes of material in a time schedule acceptable for in situ loading. ${ }^{7,11}$ Tests were generally carried out loading uniaxially a film-substrate composite, the film being stressed biaxially because of the mismatch between the Poisson's ratios of either the film and the supporting substrate ${ }^{7,11}$ or the different sublayers. ${ }^{12}$ Multiphase materials are a key area of study for diffraction-based stress or strain measurement techniques. Polymer-matrix composites have been avoided because of the difficulty in obtaining accurate diffraction data from a hydrogencontaining material. The development of synchrotron x-ray techniques offers exciting possibilities for such composite materials. Hence, we demonstrate that synchrotron XRD can

\footnotetext{
a) Author to whom correspondence should be addressed. Electronic mail: eric.le.bourhis@univ-poitiers.fr.
}

be used to monitor with accuracy both polymeric substrate and metallic film elastic strains during in situ mechanical loading.

X-ray lattice strain measurements were carried out on a laminate composite formed by a polycrystalline gold film deposited by physical vapor deposition onto a polyimide substrate from Du Pont de Nemours (registered trademark Kapton $^{\circledR}$ ). These were $127.5 \mu \mathrm{m}$ thick and $14 \times 6 \mathrm{~mm}^{2}$ in size dog-bones cleaned with ethanol before deposition. Gold films were deposited using ion-beam sputtering. Growth chamber base pressure was $7.10^{-5} \mathrm{~Pa}$ while working pressure during film growth was $10^{-2} \mathrm{~Pa}$. Deposition was carried out at room temperature with an $\mathrm{Ar}^{+}$ion beam at $1.2 \mathrm{keV}$. Films thickness was $400 \pm 10 \mathrm{~nm}$ while a strong $\{111\}$ fiber texture was obtained. ${ }^{13}$ The dog-bone samples were gripped by a Deben ${ }^{\mathrm{TM}}$ tensile tester loaded uniaxially from 0 to $25 \mathrm{~N}$ (macroscopic stress applied to the substrate-film composite from 0 to $33 \mathrm{MPa}$ ), unloaded to $9 \mathrm{~N}$ and reloaded up to $35 \mathrm{~N}$ (macroscopic stress $46 \mathrm{MPa}$ ) before complete unloading. Noticeably, a threshold load of $8 \mathrm{~N}$ is to be applied in order to prevent sample displacements that may affect the diffraction strain data. Diffraction experiments have been carried out on BM02 beamline at the European Synchrotron Radiation Facility (ESRF, Grenoble, France). X-ray diffracted signal was recorded by a MAR133 charge-coupled device (CCD) detector placed at $120 \mathrm{~mm}$ from the sample and perpendicular to the incoming beam (Fig. 1). During the experiment, the diffraction signal was recorded every $12 \mathrm{~s}$ (4 s exposure time and $8 \mathrm{~s}$ readout) while the displacements of the sample surface were recorded every $30 \mathrm{~s}$ with a CCD camera placed above the tensile tester. The $\mathrm{x}$-ray beam energy was set at $E=20 \mathrm{keV}(\lambda=0.061992 \mathrm{~nm})$ which is the beamline optimum for photon flux. XRD images were analyzed using FIT2D software ${ }^{14}$ to obtain classical $2 \theta$-intensity diagrams integrated with a step of $1^{\circ}$ along $\gamma$ (see Fig. 1). Digital optical image correlation has been carried out by DEFTAC software using four different areas taken on optical images of the sample surface.

The XRD pattern of polyimide substrate obtained on a Seifert diffractometer $(\mathrm{Cu}$ radiation, $\lambda=0.154 \mathrm{~nm}, \mathrm{E}$ $=8.04 \mathrm{keV}$, not shown here) displays three main characteristic reflections $\left(2 \theta=15,22.5,27^{\circ}\right)$ revealing its semicrystal- 


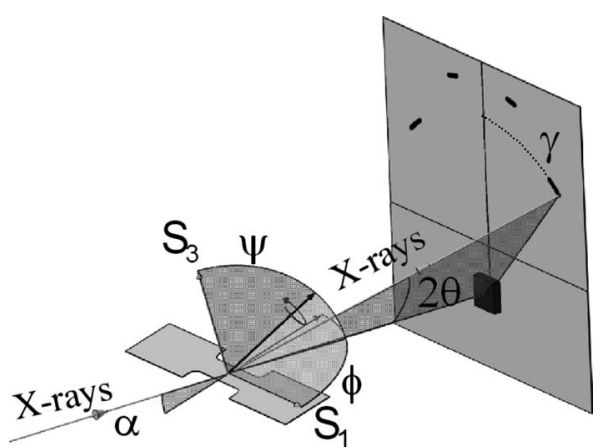

FIG. 1. Sketch of the experiment showing the loaded specimen, the 2D detector, the incident $\mathrm{x}$-ray beam, and the diffracted beam at Bragg's angle $2 \theta . \psi$ is the angle between the specimen surface normal $\mathrm{S}_{3}$ and the diffracting plane normal, $\phi$ the rotation angle of the specimen around its surface normal, $S_{1}$ is the direction of load application, $\gamma$ is the rotation angle around the detector surface normal. The Beamstop position is shown on the detector. $\alpha$ is the incident beam angle $\left(\alpha=9^{\circ}\right)$.

line nature, i.e., a mixture of crystalline and amorphous phases. Related peaks under synchrotron radiation (E $=20 \mathrm{keV})$ are obtained at smaller $2 \theta$ angles and stopped by the beamstop (Fig. 1). Figure 2 shows the x-ray intensity measured from both the coated and the bare polyimide substrates on synchrotron beamline. For the coated sample, we obtain an intense peak attributed to gold while another one appears at smaller $2 \theta$. Latter one is similar to that detected for the uncoated polyimide sample and is attributed to the substrate. Hence, using XRD we are able to monitor both film and substrate responses and extract respective strains fitting both peaks by Pearson VII functions. Changes in interplanar spacing $d_{\mathrm{hkl}}$ can be used with Bragg's law $\lambda$ $=2 d_{\mathrm{hkl}} \sin \theta$ to determine the elastic strain $\varepsilon_{\phi \psi}$ through the change in the Bragg's scattering angle $\theta$

$$
\varepsilon_{\phi \psi}=\ln \left(\frac{d_{\mathrm{hkl}}}{d_{0}}\right)=\ln \left(\frac{\sin \theta_{0}}{\sin \theta}\right) .
$$

In the present experiment, reference state $\left(d_{0}, \theta_{0}\right)$ corresponds to unloaded state. Strain results can then be converted into stress using a suitable stiffness value. Since diffraction is inherently selective and therefore based toward a particular set of grains, the peak shifts can be exploited for multiphase materials to provide information about strain or stress states of individual phases separately. It is important to note that XRD strains for polyimide are obtained for crystalline zones only. Hence, as mentioned above complementary optical

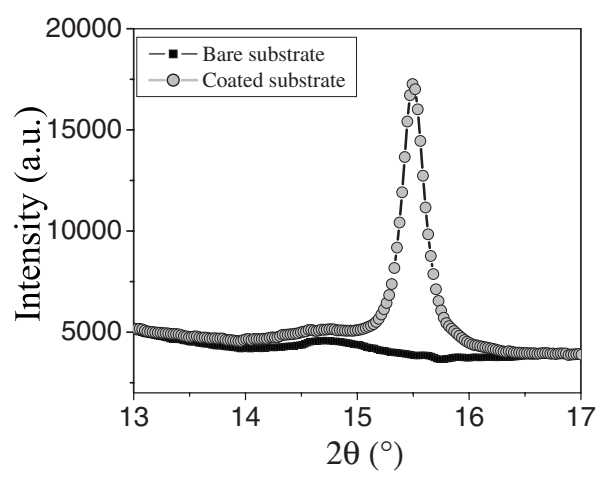

FIG. 2. XRD patterns of the bare Kapton ${ }^{\circledR}$ (square symbol) and gold-Kapton ${ }^{\circledR}$ composite (gray circles) in the region of the $\{111\}$ gold peak using synchrotron radiation $(\mathrm{E}=20 \mathrm{keV})$.

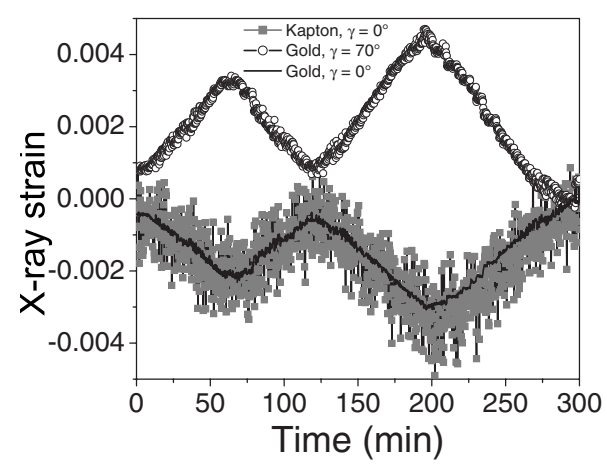

FIG. 3. X-ray strains for gold film and Kapton ${ }^{\circledR}$ substrate for different $(\phi, \psi)$ directions (i.e., different $\gamma$ angles) as a function of time. Black open circles and bold line are for gold at $\gamma=70^{\circ}$ and $0^{\circ}$, respectively. Gray squares are for Kapton ${ }^{\circledR}$ at $\gamma=0^{\circ}$.

measurements were carried out to determine the macroscopic strains that consider both crystalline and amorphous zones.

With a two-dimensional (2D) detector, strain measurements for several directions $(\phi, \psi)$ are available in a single exposure. $^{15}$ Figure 3 shows the strain evolution for two $(\phi, \psi)$ positions for gold (film) and one $(\phi, \psi)$ position for polyimide. The $\phi$ position at $90^{\circ}$ (i.e., $\gamma=0^{\circ}$, Fig. 1) corresponds to the direction perpendicular to the tensile axis. Due to the much smaller intensity of the polyimide diffraction peak, substrate $x$-ray strain data are more scattered (variance $\sim 5 \times 10^{-4}$ ) than gold ones (variance $\sim 8 \times 10^{-5}$ ). Despite the scatter, Fig. 3 clearly demonstrates that both strain evolutions for gold film and Kapton ${ }^{\circledR}$ substrate can be measured accurately for small applied deformations. We observe for gold opposite signs for strains determined along $\gamma=70^{\circ}$ and $0^{\circ}$, namely, tension and compression, respectively, as expected from Poisson's effect. Upon unloading, the strains recover elastically. Both evolutions at $\gamma=0^{\circ}$ (measured directions $\left(\phi=90^{\circ}, \psi \sim 5^{\circ}\right)$ close to each other) are very similar for the film and substrate. However, there is a small but noticeable change in the evolution of the strain in the two materials between the two cycles. Indeed, gold film and Kapton ${ }^{\circledR}$ substrate strains for the same $(\phi, \psi)$ position are identical during the first cycle. Looking more carefully at the second cycle (obtained under larger macroscopic stresses, e.g., $46 \mathrm{MPa}$ versus $33 \mathrm{MPa}$ ), we can detect that the $\mathrm{x}$-ray elastic strain is slightly larger in the substrate than in the film, this phenomenon being emphasized at the end of the cycle. To improve the observation of this phenomenon, we smoothed the polyimide data averaging over 5 consecutive points with an achieved strain resolution better than $5 \times 10^{-4}$ (taken as twice the variance $\sim 2.5 \times 10^{-4}$ ). The key factor in achieving such a strain resolution is the superior statistics obtained with the use of both high intensity synchrotron radiation and 2D detector. In summary, the strain is transmitted unchanged through the film-substrate interface during the first cycle. Both the crystalline zones in the polyimide substrate and the gold thin film behave elastically and identically within the experimental uncertainty. During the second cycle (under larger stresses), the responses deviate from each other because of the onset of plasticity in the gold film, only the elastic strains being monitored. Noticeably, Böhm et al. ${ }^{7}$ report a yield stress of $500 \mathrm{MPa}$ for similar deposited gold films which corresponds to the level of stress expected at the maximum of the second loading cycle. 


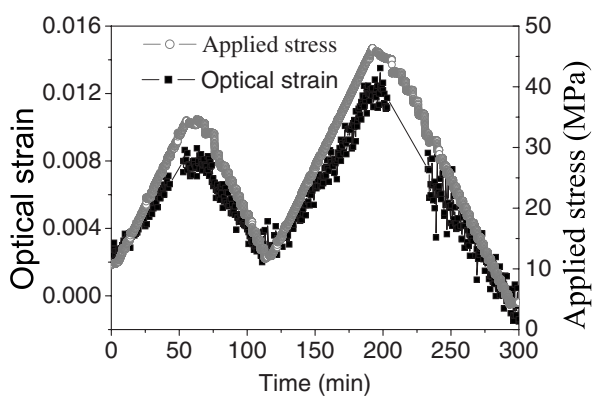

FIG. 4. Macroscopic stress applied to the substrate-film composite and macroscopic (true) longitudinal strain $\varepsilon_{11}$ as a function of time.

X-rays only interact with the crystalline part of the substrate and inform on the strain in crystalline zones. Therefore, an optical technique was used to determine the macroscopic strain which considers both crystalline and amorphous components of the substrate. Figure 4 shows the evolution of the optical longitudinal strain in the plane $\varepsilon_{11}$ and of the macroscopic stress applied to the film-substrate composite. It can be observed that the strain follows a linear evolution as the applied stress. The strain evaluated by the optical method (longitudinal $\varepsilon_{11}$ ) can be usefully compared to that obtained by XRD [e.g., $\left.\varepsilon\left(\gamma=70^{\circ}\right)\right]$. The obtained ratio $\varepsilon_{11} / \varepsilon(\gamma$ $\left.=70^{\circ}\right) \sim 2.5$ is determined to be constant over the experiment carried out in the elastic domain indicating that crystalline and amorphous zones deform elastically and similarly.

The above results show that we can consider that deformation is continuous through the metal-polymer interface in a film-substrate composite loaded uniaxially in its elastic domain (namely, for both components). This is an important result since some authors recommend the use of an interlayer in order improve the adhesion between a film and a substrate of different nature. ${ }^{7,8}$ We reveal that the Au-polyimide interface sustains elastic strains with a continuity of the deformations being observed. From the fundamental point of view, this result has also important implications since the modeling of the coated substrate (without interlayer) is much simpli- fied considering a laminate formed by the film and the substrate. ${ }^{11,13}$

The elastic strain partition in a metallic film-polymeric substrate laminate has been studied by synchrotron XRD that allows monitoring the elastic responses of both components. No intermediate interlayer between the gold film and the Kapton ${ }^{\circledR}$ substrate has been used to improve adhesion. However, we showed that there is a complete strain transfer through the film-substrate interface as long as the elastic domain is scrutinized.

The authors gratefully acknowledge the European Synchrotron Radiation Facility for provision of beamline, as well as the staff of BM02 (D2AM) beamline.

${ }^{1}$ M. A. Meyers, A. Mishra, and D. J. Benson, Prog. Mater. Sci. 51, 427 (2006).

${ }^{2}$ E. Arzt, Acta Mater. 46, 5611 (1998).

${ }^{3}$ S. P. Lacour, S. Wagner, Z. Huang, and Z. Suo, Appl. Phys. Lett. 82, 2404 (2003).

${ }^{4}$ Y. Xiang, T. Li, Z. Suo, and J. J. Vlassak, Appl. Phys. Lett. 87, 161910 (2005).

${ }^{5}$ M. Hommel and O. Kraft, Acta Mater. 49, 3935 (2001).

${ }^{6}$ D. L. Pappas and J. J. Cuomo, J. Vac. Sci. Technol. A 9, 2704 (1991).

${ }^{7}$ J. Böhm, P. Grüber, R. Spolenak, A. Stierle, A. Wanner, and E. Arzt, Rev. Sci. Instrum. 75, 1110 (2004).

${ }^{8}$ M. K. Ghosh and K. L. Mittal, Polyimides: Fundamentals and Applications (Marcel Dekker, New York, 1996).

${ }^{9}$ V. Hauk, Structural and Residual Stress Analysis by Non Destructive Methods: Evaluation, Application, Assessment (Elsevier Science, Amsterdam, 1997).

${ }^{10}$ I. C. Noyan and J. B. Cohen, Residual Stresses: Measurements by Diffraction and Interpretation (Springer, New York, 1987).

${ }^{11}$ P.-O. Renault, E. Le Bourhis, P. Villain, Ph. Goudeau, K. F. Badawi, and D. Faurie, Appl. Phys. Lett. 83, 473 (2003).

${ }^{12}$ N. A. Mara, D. Bhattacharyya, R. G. Hoagland, and A. Misra, Scr. Mater. 58, 874 (2008).

${ }^{13}$ D. Faurie, P.-O. Renault, E. Le Bourhis, and Ph. Goudeau, J. Appl. Phys. 98, 093511 (2005).

${ }^{14}$ A. Hammersley, S. Svensson, and A. Thompson, Nucl. Instrum. Methods Phys. Res. A 346, 312 (1994).

${ }^{15}$ G. Geandier, P. O. Renault, S. Teat, E. Le Bourhis, B. Lamongie, and P. Goudeau, J. Appl. Crystallogr. 41, 1076 (2008). 